\title{
Ação Afirmativa: instrumento de cidadania ou discriminação reversa?
}

\section{Affirmative Action: instrument of citizenship or discrimination reverse?}

\author{
Alexandre Sturion de Paula ${ }^{1}$
}

\begin{abstract}
Resumo
A ação afirmativa, cujos primeiros traços datam da década de 30, só ganhou contorno nos EUA a partir de meados do século XX. A ação afirmativa consiste num programa que objetiva resgatar a própria cidadania de indivíduos marginalizados pela sociedade em razão de discriminações, que não necessariamente a racial, como se tem conotado no Brasil. Não se confunde, entretanto, com o mero estabelecimento de política de quotas, dada a possibilidade de outros programas relacionados à ação afirmativa. É forçoso afirmar, contudo, que os programas de ação afirmativa brasileiros concentram-se em demasia sobre política de emprego de quotas para cidadãos negros. Posicionamentos contrários ou favoráveis à instituição de quotas passaram a ser levantados. Os princípios insertos na Constituição apresentam a permissibilidade de fomentação de ações afirmativas. Entretanto, as quotas que ora se pretendem instituir com percentuais de até $40 \%$ para cidadãos negros, inegavelmente, representam uma discriminação reversa. Concluí-se, portanto, que as discussões, ora mais ora menos acirradas acerca da instituição de quotas para cidadãos negros e pardos, no fundo, consistem no exercício de cidadania no tocante a junção de forças críticas para que direitos sejam garantidos e efetivamente viabilizados. Palavras-chave: Ação afirmativa. Quotas. Ensino superior. Cidadania. Discriminação reversa.
\end{abstract}

\begin{abstract}
Affirmative action can be traced back to 1930, but it became widely known in the US in the middle of the Twentieth Century. The objective of affirmative action programs is to reclaim the citizenship of individuals rejected by the society due to discriminations other than racial, as in the case of Brazil. Therefore, these programs should involve more than the mere establishment of quotas, which is only one among many other affirmative action possibilities. It is important to emphasize that Brazilian affirmative action employment programs have relied strongly on the policy of quotas for black citizens. This has triggered a number of favorable and unfavorable reactions towards the implementation of quotas in Brazil. Constitutional principles have guaranteed the development of affirmative action programs; therefore, the establishment of quotas to protect the rights of $40 \%$ of blacks to attend university is a clear example of reverse discrimination. Thus the heated discussions on the implementation of quotas for blacks and mulattos are nothing but an exercise in citizenship to join critical forces to guarantee constitutional rights.
\end{abstract}

Key words: Affirmative action. Quotas. University education. Citizenship. Reverse discrimination.

\footnotetext{
1 Advogado, Pós-graduando em Direito do Estado/UEL. Rua: Minas Gerais, 194, $5^{\circ}$ andar, sl. 513. Ed. Autolon. Centro. LondrinaPR. CEP: 86010-170. Fone/fax: 3322-1362. E-mail: alexandresturion@yahoo.com.br

2 A Constituição da Namíbia de 1990, em seu artigo 23 condenou o Apartheid e positivou a ação afirmativa.
} 


\section{Intróito: o que é fato?}

A história brasileira, como, de resto, a do próprio continente americano, tem no trabalho escravo e na subjugação do homem negro uma triste nódoa. Durante séculos, houve discriminações abertas contra a população negra, quando não perseguições legais e sistemáticas contra brancos que se unissem ou apoiassem em qualquer sentido um homem negro. Também é inegável a presença, em pleno Terceiro Milênio, de atitudes racistas por parte de muitos homens brancos em detrimento dos cidadãos de pele negra, muito embora cresçam as tentativas e cristalizações de algumas mudanças no sentido de se romper com esta injustificada separação racial.

Os norte-americanos, foco de atenção quando se cogita de reflexões sobre alguns paradigmas societários, com propriedade representam a nascente de grande parte dos estudos que hoje se fazem acerca da discriminação racial. O Brasil tem avançado nesta discussão, inclusive com inclusão de legislações protetoras. No entanto, considerando o contingente populacional de negros no país, bem como a sua importância histórica na construção da nação, tem-se que a importância que se começa a dar à questão já se faz tardia. Neste sentido enfatiza Inocêncio (2004) que:

Aproximadamente cinqüenta anos depois do Estado estadunidense ter assumido publicamente as desigualdades entre brancos e negros, o Estado brasileiro começa a dar seus primeiros passos tentando lidar com as dificuldades impostas por sua decisão tardia, mesmo tendo o país participado oficialmente de vários fóruns das Nações Unidas visando a superação das desigualdades raciais desde a década de sessenta.

A questão, ao que nos parece, não mereceria tamanho embate, não fossem as polêmicas oriundas da importação de concepções da affirmative action norte-americana como modelo para a solução da discriminação racial brasileira. O alvoroço passou a ganhar destaque quando da instituição de quotas para negros em concursos públicos, vagas universitárias, benefícios financeiros, dentre outros programas. Verifica-se, pois, que enquanto apenas os cidadãos negros exigiam seus direitos, constitucionais inclusive, e o Governo apenas ouvia suas queixas, a sociedade em geral permanecia na inércia. Entretanto, quando o Estado passou a inferir na questão, por meio de seu imperium com programas de ação afirmativa, a celeuma ganhou relevo, passando a ser alvo de discussões entre sociólogos, juristas, pedagogos, filósofos, economistas, enfim, a sociedade ativa em geral. Neste escólio, ressalta Poletti (2004) que:

As ações afirmativas estão na moda. Em todo o País se discute a discriminação positiva. Há uma lei estadual impondo cotas para os negros nas universidades. O novo Ministro do Supremo Tribunal Federal, Doutor Joaquim Barbosa Gomes, é autor de um livro intitulado "Ação Afirmativa, princípio constitucional da igualdade (O direito como instrumento de transformação social: A experiência nos Estados Unidos)" e de um artigo (A recepção do instituto da ação afirmativa pelo Direito Constitucional Brasileiro). Na UnB, a bacharelanda Deborah Dettmam Maia discorreu com brilho sobre o tema em sua monografia final de curso.

Cabe ressaltar, porém, que os programas de ação afirmativa que ora despontam-se não representam as primeiras iniciativas de trazer solução aos problemas oriundos da discriminação racial, visto que há tempos tais discussões se enredam. Segundo Santana (2004), a questão remonta há décadas, pois já no próprio século XX a sociedade brasileira apresentava a nascente de tais discussões com "um importante debate desencadeado pelo movimento negro contemporâneo referente à problematização da formal democracia racial brasileira, denunciando a hierarquia das raças que se cristalizou em nosso país e que se institui como reguladora das relações sociais”.

Conquanto se tenha avançado no debate em torno da temática, verifica-se que os fatos presentes da realidade ainda são gravosos e merecedores de especial atenção, visto que as desigualdades raciais promovem exclusões irracionais e sob o crivo da omissão coletiva da sociedade. A pedagoga Olívia Santana (2004) ainda salienta que: 
Dados do IPEA de 2000, uma das mais completas pesquisas que temos notícia com o corte racial, constata a inalterada situação do fosso que separa negros e brancos na estrutura social brasileira ao longo de todo o século XX.

Os dados do IPEA dão conta de que $64 \%$ da população pobre é negra contra $36 \%$ de brancos; $69 \%$ dos indigentes são negros; contra $31 \%$ de brancos. Traduzindo em números absolutos temos 33,7 milhões de brasileiros negros vivendo em condição de pobreza e 15,1 milhões vivendo em condição de indigência absoluta. Entre os brancos são 19 milhões de pobres e 6,8 milhões de brancos indigentes. Os negros representam 70\% dos 10\% da população mais pobre do país, enquanto que os brancos somam $85 \%$ dos $10 \%$ da população mais rica. São dados que configuram o que podemos chamar de retrato em branco e preto da exclusão social no Brasil. Os indicadores sociais seguem dando conta de que, em média, um trabalhador branco ganha $\mathrm{R} \$ 573,00$ mensais, enquanto que um trabalhador negro ganha $\mathrm{R} \$ 262,00$. Mesmo tendo o mesmo nível de formação que um trabalhador branco, o trabalhador negro tende a ganhar um salário 30\% a $50 \%$ menor.

Estes dados contextualizam a importância da temática, dando vazão a estudos mais profundos acerca da ação afirmativa, do princípio constitucional da igualdade e do próprio exercício da cidadania. Estes estudos não se encerram na discussão sociológica, mas ultrapassam áreas de conhecimento. Dentre as ciências que se obrigam a contribuir com o debate, por certo está a jurídica, uma vez que os ordenamentos jurídicos representam forte alicerce para contribuição com a viabilidade e eficácia dos direitos de cidadania do homem negro. De se dizer, no entanto, que este não é o entendimento de todos. Poletti (2004) afirma que:

A discussão parece situar-se mais no campo da ação política do que na ciência jurídica. Se jurídico, mais no direito dos Estados Unidos da América do que no nosso. As ações afirmativas são estratégias político-sociais, cuja adoção pelo Presidente
Kennedy provocou uma série de acontecimentos, que tiveram lá repercussão constitucional, por força de um direito sociológico e de uma Constituição sintética com normas em branco, em uma federação diferente da nossa, em um diverso sistema jurídico, com outros problemas históricos quanto à escravidão e ao racismo (basta ler Alexis de Tocqueville). Aqui não cabe a idéia do direito como instrumento de transformação social e muito menos de revolução. Os movimentos sociais repercutem na elaboração, aplicação, interpretação do direito. Não mais que isso.

A par do respeito que se presta ao entendimento acima, cabe afirmar que não é esta a nossa concepção. Embora, de fato, a questão resida com maior propriedade no campo da ação política, a sua essência, no Brasil, está caracteristicamente impregnada na cultura e nos costumes transpassados por décadas. Dessarte, trata-se de uma discussão em que todos são sujeitos, pois os direitos do ser humano estão sendo cotejados. Assim, por conseqüência, essa questão exige a presença da ciência jurídica, pois esta deve demonstrar-se capaz de acobertar as necessidades que a ordem social reclamar, antes mesmo de pretensões de transformações sociais via direito.

Há que se cuidar, porém, com exageros e defesas xiitas de um ou outro posicionamento mais emotivo e menos racional. Tostes (2004) preceitua que “de fato, umas das principais obsessões dos defensores da 'ação afirmativa' parece ser a de demonstrar que há racismo no Brasil”. O contexto da ação afirmativa caminha de forma muito tênue com discussões isoladas em torno dos motivos pretéritos que induziram e/ou que induzem a permanência ou não do racismo. Estes debates não conduzem ao cerne de um ponto pacífico que é a igualdade constitucional a todo cidadão, independente da cor de sua pele.

Por se a discriminação racial um fato notório, desejamos contribuir par ao debate. Isso será feito com um melhor esclarecimento do conceito e origem da affirmative action, da apresentação de posicionamentos favoráveis e contrários ao emprego de programas de ação afirmativa, e da sua inserção 
no ordenamento jurídico pátrio. Como o estudo enfoca a discriminação racial, será analisada a polêmica sobre a instituição de quotas para cidadãos negros como viabilização de políticas de ações afirmativas.

\section{Conceito de Ação Afirmativa}

Antes mesmo de traçar a origem do instituto, é de grande relevância o entendimento exato do que realmente vem a consistir a ação afirmativa, a affirmative action norte-americana. Ela se propagou por vários países em diversos continentes, inclusive sedimentando-se em algumas Constituições longínquas da América, como a da Namíbia². Também é salutar fazer distinções entre o que se associa ou não à expressão em questão, visto que sua própria denominação pode conduzir a alguns equívocos que explanaremos. Assim, por se tratar de nascente do instituto, pejorativo a sua análise a partir da ótica anglo-saxônica. Segundo Menezes (2001, p.28):

Uma visão sintética é apresentada por Kent Greenawalt: 'ação afirmativa é uma expressão que se refere às tentativas de trazer membros de grupos sub-representados, normalmente grupos que sofrem discriminação, a um grau mais alto de participação em algum programa de benefício’.

Como se pode observar, grosso modo, trata-se de um apoio às minorias, ou classes subjugadas, seja em decorrência de sua cor, religião, origem, etc. Nesse sentido, também segue posicionamento jurisprudencial anglo-saxão. Menezes (2001, p.28) salienta que a Suprema Corte do Canadá, com base na lição de Laycraft J. A., decidiu:

Termos e condições impostos em benefício de grupos que sofrem desvantagens econômicas e sociais, normalmente como resultado de discriminação passada, e destinados a auxiliá-los a alcançar igualdade com outros segmentos da população são denominados programas de 'ação afirmativa'.

A ação afirmativa consiste, num programa entabulado pelos diversos Estados e teve com gênese no Estado estadunidense. Esse programa objetiva resgatar, em essência, a própria cidadania de indivíduos que estão marginalizados de toda a sociedade e do sistema como um todo em razão de discriminações, que não necessariamente a racial, como se tem conotado no Brasil. Ele constitui, ainda, num modelo de enfrentamento ao próprio preconceito, a partir de suas práticas de oferta de oportunidades às classes discriminadas, o que envolve questões políticas, culturais e jurídicas. O sociólogo Eduardo H. P. de Oliveira (2004) leciona que:

Apesar de o exemplo norte-americano ter se transformado numa espécie de paradigma, as políticas de ação afirmativa no combate às desigualdades culturais também estão sendo utilizadas em países tão díspares como Ilhas Fidji, Malásia, Canadá, Índia e Austrália- no que se refere às desigualdades étnico- raciais -, e EUA, Canadá e a grande maioria dos países europeus, no que diz respeito às desigualdades entre gêneros.

Não fugindo à praxe, o Brasil também começa a debater o programa de ação afirmativa, embora tenha feito décadas após sua gênese nos Estados Unidos da América. Todavia, no Brasil, houvera uma delimitação da ação afirmativa, até mesmo em decorrência da própria necessidade emergente. Desta forma, a ação afirmativa brasileira passou a enfocar sobremaneira a discriminação racial, sem despojar cuidados sobre as necessidades dos deficientes físicos e das mulheres, que compõe as minorias discriminadas no país. Assim, a

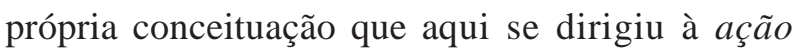
afirmativa passou a conceber esta restrição. É neste escólio que Silva (2004) traz a lição do então membro do Ministério Público Federal, hoje Ministro do Supremo Tribunal Federal, Joaquim B. Barbosa Gomes, que ensina:

As ações afirmativas 'consistem em políticas públicas (e também privadas) voltadas à concretização do princípio constitucional da igualdade material e à neutralização dos efeitos da discriminação racial, de gênero, de idade, de origem nacional e de compleição física. Impostas ou sugeridas pelo Estado, por seus entes vinculados e até mesmo por entidades puramente privadas, elas visam a combater não somente as 
manifestações flagrantes de discriminação de fundo cultural, estrutural, enraizada na sociedade’.

O Ministro ainda levanta uma classificação acerca das ações afirmativas, ao afirmar que estas derivam de decisões políticas que envolvem os Três Poderes, sendo que o Executivo elabora as decisões, o Legislativo as sustenta e vigia, e o Judiciário apõe a legitimidade aos programas encetados, além de ele próprio promover ações afirmativas, assim como a própria iniciativa privada.

Em geral, tem-se que a conceituação da affirmative action não encontrou forte mutação quando em solo diverso do ianque, tão-somente fora afunilado seu conceito em direção às necessidades próprias de cada nação, como é o caso do apartheid africano, as etnias européias, o racismo brasileiro.

Com o objetivo de "implementar uma igualdade concreta (igualdade material), no plano fático, que a isonomia (igualdade formal), por si só não consegue proporcionar” (MENEZES, 2001, p.29), alguns equívocos podem surgir sem guardar razão com o conceito e os fins da ação afirmativa. Assim, há que se ter claro que alguns mal-entendidos não podem perdurar. A primeira confusão consiste no fato de associar a ação afirmativa com quotas, o que, analisada a affirmative action, não procede, devido à existência de outros programas relacionados à ação afirmativa que não as quotas. Muito embora os programas de ação afirmativa brasileiros concentrem-se em demasia sobre o emprego de quotas, como se verá a seguir, não significa dizer que sejam sinônimos, posto que o sistema de quotas representa uma das contribuições da ação afirmativa.

Menezes (2001, p.32) ministra que outro engano é conceber as ações afirmativas como oriundas tãosomente de "iniciativas oficias ou programas previstos em lei”, visto a possibilidade e efetiva realização de "programas de ação afirmativa voluntários, elaborados espontaneamente por empresas privadas”. Outra freqüente incorreção, também salientada por Menezes (2001, p.33), deve-se ao fato de que, em razão das questões relacionadas à ação afirmativa buscarem soluções judiciais, promovendo um grande número de processos, há "mais uma imperfeição, bastante comum, que é a de identificar a ação afirmativa como sendo um 'remédio' ou uma 'solução judicial', como se esta fosse apenas reflexo direto de decisões judiciais”

Dentre as impropriedades acima, a que mais se relaciona às concepções brasileiras sem dúvida referem-se às quotas, que como já afirmado não são ação afirmativa propriamente dita, mas derivação desta. Dessarte, cumpre destacar, preliminarmente, o que vem a ser as quotas.

Silva (2004) leciona que:

De início, uma coisa é certa: as cotas, como são denominadas certas políticas públicas mais radicais objetivando a concretização da igualdade material, nasceram no bojo das ações afirmativas, mas com essas não se confundem. É nesse sentido, que o prof. Jorge da Silva, da UERJ, é enfático ao dizer que a ação afirmativa não 'é simplesmente o estabelecimento de 'quotas' percentuais para negros'. [...] As cotas são uma segunda etapa das ações afirmativas. Constatada nos EUA a ineficácia dos procedimentos clássicos de combate à discriminação, deu-se início a um processo de alteração conceitual das ações afirmativas, que passou a ser associado à idéia, mais ousada, de realização da igualdade de oportunidades através da imposição de cotas rígidas de acesso de representantes de minorias a determinados setores do mercado de trabalho e a instituições educacionais. Data também desse período a vinculação entre ação afirmativa e o alcance de certas metas estatísticas concernentes à presença de negros e mulheres num determinado setor do mercado de trabalho ou numa determinada instituição de ensino.

Fica patente pois, que o estabelecimento de quotas representam seqüência e não fundamento da ação afirmativa. Essas consistem em um polêmico instrumento que passa a ser empregado pelo Brasil para garantir o acesso das minorias, mormente àquelas oriundas da discriminação racial, às condições mais igualitárias de acesso ao emprego público ou banco universitário. No entanto, vez mais se diga, as ações afirmativas possibilitam outros programas 
diversos das quotas para a sua eficácia, tais como, segundo Silva (2004):

O método do estabelecimento de preferências, o sistema de bônus e os incentivos fiscais (como instrumento de motivação do setor privado). De crucial importância é o uso do poder fiscal, não como mecanismo de aprofundamento da exclusão, como é da tradição brasileira, mas como instrumento de dissuasão da discriminação e de emulação de comportamentos (públicos e privados) voltados à erradicação dos efeitos da discriminação de cunho histórico.

Feitas estas considerações que deixam claro os objetivos e o próprio conceito do que venha a ser a ação afirmativa, assim como a correta distinção de seu conceito com algumas assimilações errôneas, é oportuno apresentar, de forma sucinta, a origem da affirmative action que se propaga em todo o globo.

\section{Origem}

Apenas para trazer a noção da raiz da ação afirmativa que ora passa a ser discutida com maior ênfase pela sociedade brasileira, bem como para situar no tempo e no espaço o instituto, é relevante salientar a singela gênese da affirmative action. Assim temos que os primeiros traços da ação afirmativa datam da década de 30, no entanto, só foram ganhar contorno nos EUA a partir de meados do século XX com a instituição de legislações de direitos civis. Ressalte-se, também, a importância de organizações, movimentos e lideranças para a construção de programas em benefícios aos discriminados, tais como a NAACP - National Association for the Advancement of Colored People, os movimentos negros e seus líderes como Martin Luther King, Malcon X e os Panteras Negras.

Salutar para o contexto examinado os ensinamentos históricos de Oliveira (2004) ao ministrar que:

Nos Estados Unidos, o termo Ação Afirmativa Affirmative Action - surgiu pela primeira vez em 1935 no Ato Nacional de Relações de Trabalho, através do qual ficava proibido ao empregador exercer qualquer ato repressivo contra um membro de sindicato ou seus líderes e, ainda, parar de discriminar usando mesmo de ação afirmativa para colocar suas vítimas numa posição em que eles teriam atingido se não houvessem sido discriminados[...]. No contexto da luta pelos direitos civis, o termo apareceu primeiro na Ordem Executiva 10925 do presidente John F. Kennedy, de 6 de março de 1961. Nela, o presidente proibia as diversas agências governamentais de discriminarem seus candidatos por bases de cor, religião e nacionalidade, estimulando-as para que usassem de ação afirmativa na contratação de seus empregados. Com a morte de Kennedy, foi o presidente Lyndon Johnson quem mais avançou na intenção de criar mecanismos de combate à desigualdade. Com a Ordem Executiva 11246, Johnson estimula as firmas contratadas pelo Governo a buscarem de ação afirmativa para garantir igualdade de oportunidade para membros de minorias e deficientes físicos, e proíbe a discriminação.

Num caminho antagônico aos trilhados pelo atual presidente dos Estados Unidos da América, George W. Bush, seus antecessores John F. Kennedy e Lyndon Johnson exerceram papeis de imprescindível relevância para o avanço de políticas de ação afirmativa. O então Presidente Kennedy tomou a questão como plano de governo, fazendo empenho pessoal para que fossem aprovadas leis no sentido de acabar com a discriminação racial. Menezes (2001, p.88) salienta que:

A 'Executive Order' n. 10.925, que, afora criar um órgão para fiscalizar e reprimir a discriminação existente no mercado de trabalho ('President's Comittee on Equal Employment Opportunity'), empregou pela primeira vez em um texto oficial, ainda que com uma conotação restrita, o termo 'affirmative action'. De acordo com essa ‘Executive Order', nos contratos celebrados com o governo federal, 'o contratante não discriminará nenhum funcionário ou candidato a emprego devido a raça, credo, cor ou nacionalidade. O contratante adotará ação afirmativa para assegurar que os candidatos sejam empregados, como também tratados durante o emprego, sem consideração a sua raça, seu credo, 
sua nacionalidade. Essa ação incluirá, sem limitação, o seguinte: emprego; promoção; rebaixamento ou transferência; recrutamento ou anúncio de recrutamento, dispensa ou término; índice de pagamento ou outras formas de remuneração; e seleção para treinamento, inclusive aprendizado'.

Embora se tenham descritos fatos históricos concentrados no século XX, há de se ressaltar que outros fatores pretéritos contribuíram para que os norte-americanos consolidassem a affirmative action, tais como já as próprias Décima Terceira e Décima Quarta Emendas constitucionais, de 1865 e 1868, respectivamente. A primeira abolia a escravidão, a segunda contemplou a equal protection clause. Todavia, a discussão judicial em torno destas disposições foram acirradas, não sendo raras as disparidades até a presente data.

A invocação por negros da igualdade jurídica estampada pela Décima Quarta Emenda fora alvo de várias decisões antagônicas da Suprema Corte ianque, tais como os casos Dred Scott v. Sandford; Strauder v. State of West Virginia; Pace v. Alabama; dentre outros. No primeiro caso um escravo de um cirurgião militar requer sua liberdade, após a morte do cirurgião, com o embasamento de que, em face de ter permanecido em territórios cuja escravidão era abolida, havia garantido o direito à liberdade, conforme o princípio once free, always free. Todavia, a Suprema Corte negará-lhe o pedido numa decisão que manchou a Corte. Entre os fundamentos da decisão consta que Scott não possuía legitimidade para o requerimento, visto que a sua condição de negro retirava-lhe o status de cidadão norteamericano.

No segundo caso, Strauder v. State of West Virginia, discutia-se a constitucionalidade de uma lei estadual que excluía a possibilidade de negros atuarem como jurados. A Suprema Corte, neste caso, entendeu que a lei estadual violava a Décima Quarta Emenda, o que reconheceu o direito de um negro ser jurado. No terceiro caso Pace v. Alabama, discutiase a proibição, constante em uma lei estadual, de casamentos inter-raciais. A Suprema Corte decidiu pela constitucionalidade da lei, visto que como a pena atingia a um branco e um negro na mesma proporção, não havia discriminação racial, permanecendo a lei proibindo o casamento inter-racial, entendimento que perdurou até a análise do caso Loving v. Virginia, quando então a Suprema Corte entendeu inconstitucional tal discriminação racial.

Sem delongas, esses foram os principais fatos que marcaram a gênese da ação afirmativa até os dias atuais, ressaltando-se que dentro da própria sociedade estadunidense a questão está longe de ser uníssona, encontrando enfoques diversos, embora já se tenha arraigado pelo mundo à fora os ideais da affirmative action.

\section{Posicionamentos favoráveis e contrários à ação afirmativa}

Centrando a discussão sobre a análise da política de ação afirmativa brasileira, pode-se antever um embate voraz, visto que os norte-americanos, mesmo com o largo debate que já perdura mais de cinqüenta anos, ainda não chegaram a um consenso, muito mais o Brasil, que iniciou as discussões com maior propriedade neste início de milênio, mormente a partir da III Conferência Mundial de combate ao racismo, discriminação racial, xenofobia e intolerância correlata, realizado em Durban, na África do Sul, em 2001.

Ademais, um agravante é que a ação afirmativa brasileira vem erroneamente traduzindo-se em mero sistema de quotas, o que faz gerar uma celeuma ainda maior em razão de posicionamentos contrários à idéia de se destinar um determinado percentual de vagas, seja no mercado de trabalho ou sistema educacional, a negros, além de deficientes e mulheres. Daí a discussão de se estar impondo com a ação afirmativa uma discriminação reversa, ou seja, o branco acaba sendo preterido em condições de igualdade com o negro através de políticas notadamente estatais. 
Santana (2004) destaca que:

O governo Federal, durante a realização da conferência Mundial Contra o Racismo, lançou, açodadamente, a proposta de cotas para negros na universidade, o que caiu como uma bomba no seio da sociedade. Aliás, uma sociedade que não foi preparada para lidar com a questão, principalmente quando esta aparece descolada de um contexto de outras medidas necessárias para garantir a credibilidade e as possibilidades de sucesso da cota.

A citada Conferência de Durban, de setembro de 2001 influiu no contexto brasileiro. Com o próprio processo preparatório para a Conferência surgiram maiores debates sobre a adoção de políticas de ação afirmativa para pessoas negras no Brasil, antes consideradas pretensões utópicas. A socióloga Rosana Heringer (2002, p.56) afirma que "um aspecto importante desse processo foi o posicionamento público de alguns representantes do governo, especialmente do Ipea (Instituto de Pesquisa Econômica Aplicada, vinculado ao Ministério do Planejamento)”.

Posicionamentos outros, contrários ou favoráveis às propostas da ação afirmativa, em especial a de quotas, passaram a ser levantados. Santana (2004) descreve posição do então Ministro da Educação, Paulo Renato, afirmando que quando do início das discussões acerca da proposta de quotas universitárias para negros o Ministro:

Já tentou fulminar a proposta externando publicamente e duramente sua posição contrária à medida. Questionou os dados do IPEA e afirmouse favorável ao investimento do Estado em políticas universais, que, segundo ele, já estão em curso no sistema educacional brasileiro. Sabemos entretanto, que o mal já está feito e as políticas universalistas não são suficientes para garantir que negros se equiparem a brancos em termos educacionais. Há uma diferença média de 2,5 anos de estudo a mais na formação dos brancos. Os negros são apenas 2,2\% dos universitários que se formam no Brasil. Política com recorte racial é fundamental para se alterar este quadro.
O próprio posicionamento do Ministério da Educação já se alterou, já que o atual Ministro da Educação, Tarso Genro, tem defendido a idéia de quotas para negros nas Universidades, inclusive para as Universidades privadas. E a prática já começa a materializar os debates, basta observar o número de Universidades públicas que já destinam quotas para negros em seus processos vestibulares.

Este posicionamento favorável às quotas também já fora alvo de análise do então Presidente do Supremo Tribunal Federal, Ministro Marco Aurélio de Mello, que defende a adoção de políticas de ação afirmativa, no entanto, impõe ressalvas à sua duração ao dizer, segundo Heringer (2002, p.58), que "no sistema de quotas deverá ser considerada a proporcionalidade, a razoabilidade, dispondo-se, portanto, de estatísticas. Tal sistema há de ser utilizado para correção de desigualdades. Assim, deve ser afastado tão logo eliminadas essas diferenças”.

Verifica-se que a sensatez do posicionamento acima demonstra a preocupação com a ocorrência de discriminação reversa, que em nosso entendimento fatalmente ocorrerá no lapso em que perdurar o emprego de sistema de quotas. A discussão, antes mesmo de ser avaliada se é justa ou injusta, deve restringir-se à compreensão de ser ou não necessária e a mais adequada dentre tantas possibilidades que as ações afirmativas ofertam, assim como sua compatibilidade com o texto constitucional. Heringer (2002, p.59) preconiza que:

As políticas de ação afirmativa devem incluir um leque, um cardápio de ações em diferentes áreas de atuação, envolvendo o mercado de trabalho (setores público e privado e o terceiro setor); as compras e contratos governamentais; e a educação (ensino fundamental, médio e ensino superior).

Este leque, por sinal, deve apresentar modelos que contemplem um meio-termo, evitando-se radicalismos extremados. Por tais razões, o debate induz a outras questões mais profundas acerca da ação afirmativa, com reflexo sobre a política de quotas, tais como a tentativa de encontrar o 
posicionamento das ações afirmativas como sendo uma forma de justiça compensatória ou se se trataria de uma justiça distributiva. Menezes (2001, p.35) ressalta que os defensores da primeira entendem que a "ação afirmativa representaria um ressarcimento por danos causados, pelo Poder Público ou por determinadas pessoas (físicas ou jurídicas), a grupos sociais identificados ou identificáveis”. Entretanto, prossegue salientando que:

Para que a ação afirmativa não represente uma ‘discriminação reversa' contra aqueles não abrangidos pela política de favorecimento, é imprescindível, de um lado, que somente os responsáveis pelos atos discriminatórios sejam penalizados e, de outro, que apenas as vítimas reais - reconhecidas individualmente - sejam de alguma forma ressarcidas, e, ainda assim, de maneira proporcional aos danos sofridos (MENEZES, 2001, p.35).

A concepção de ação afirmativa sob o enfoque da justiça compensatória, que é o norte dos defensores das quotas, não contempla a ressalva mencionada acima. Embora aparente consistir num modelo justo, na prática apresenta-se inviável, visto a dificuldade de se mensurar ou delimitar os sujeitos envolvidos. No entanto, segundo Menezes (2001, p.36), seus defensores mais extremados advertem que "as diferenças sociais cristalizadas ao longo dos séculos somente serão suplantadas por meio de uma verdadeira 'discriminação reversa', ainda que temporária, em favor dos grupos marginalizados”. Encontramos um exemplo moderado do referido posicionamento nas afirmações de Silva (2004) ao discorrer que:

As análises estatísticas das relações raciais no Brasil ratificam o quanto o escravismo influenciou na estratificação social, sobretudo na concentração racial da riqueza.

Por isso, as ações afirmativas e as cotas são dois dos principais meios que podem ser utilizados como instrumentos capazes de propiciar mobilidade social ao afro-brasileiro, afim de integrá-lo econômica e socialmente aos demais membros da sociedade inclusiva, sem olvidar outras formas mais fecundas de obter justiça social.

De outro lado, temos a ação afirmativa vislumbrada sob a ótica da justiça distributiva. Menezes (2001, p.38) ensina que:

Para os adeptos dessa linha doutrinária, a ação afirmativa estaria relacionada a uma igualdade proporcional, exigida pelo bem comum, na distribuição de direitos, privilégios e ônus entre os membros da sociedade, que pode ser implementada por meio de vários artifícios. De fato essa distribuição pode ser efetuada com base na igualdade de oportunidades, necessidade, esforços, utilidade e outros critérios, como aqueles apresentados por John Rawls, em sua obra 'Uma teoria de justiça', extremamente conhecida no meio jurídico norte-americano.

Na doutrina alienígena, temos um adepto de renome desta concepção de justiça, trata-se de Ronald Dworkin, que “defende a ação afirmativa sob o prisma distributivo, ainda que calcado em argumentos voltados para a utilidade social” (MENEZES, 2001, p.38). A doutrina brasileira que defende o emprego da ação afirmativa, inelutavelmente tem nela o enfoque da justiça compensatória, pois há o entendimento, não raras vezes extremado, de que o fato de o país ter usufruído por enorme tempo do trabalho escravo, impregnando a cultura discriminatória contra o negro de hoje, há de se compensar a marginalização por qual vive o cidadão de pele negra, daí a defesa de uso de quotas como um dos instrumentos que promovam um crescimento ou afirmação da cidadania dos cidadãos negros. A discriminação reversa seria um malefício ínfimo se comparado a subjugação secular dos negros.

Os adeptos da ação afirmativa, contudo, são uníssonos em afirmar ainda que não basta a instituição de quotas por si só, há a necessidade de que essas propostas venham "acompanhadas de outras medidas de cunho social, tais como: melhorias na qualidade do ensino público fundamental; políticas de redistribuição de renda; reforma tributária; reforma agrária, etc” (SILVA, 2004). O próprio ex- 
presidente dos Estados Unidos da América, Lyndon Johnson apresentava o mesmo entendimento sobre a necessidade de políticas concomitantes. É famoso seu discurso na "Howard University - a universidade da elite negra, em Washington-, onde dizia que não se pode pegar alguém que esteve preso pelos pés por muito tempo, botá-lo na linha de largada e dizer: pronto, agora você pode competir com todos os outros” (OLIVEIRA, 2004). No Brasil ainda temos relevante lição de Severino (2004), que preceitua:

Certamente, garantir a segmentos significativos de jovens afrodescendentes a oportunidade de cursar o ensino superior e de se profissionalizar nesse nível é uma medida relevante. Mas criar um regime de cotas, desvinculado de outras medidas concretas e efetivas de apoio, é condená-los ao fracasso, pelo simples motivo que a grande maioria dos beneficiários dessas cotas serão homeopaticamente "eliminados" do ensino superior ao longo do processo. Quem conhece por dentro o processo social e pedagógico presente em nosso sistema de ensino, sabe muito bem da força anônima e impessoal de segregação e de rejeição que leva pessoas “diferentes e fragilizadas” a tomarem a decisão de se retirar por conta própria, sem nenhuma pressão explícita visível, por parte de quem quer que seja.

Outrossim, temos alguns posicionamentos não menos radicais contrários ao emprego de ações afirmativas, mormente o estabelecimento de quotas. Os embasamentos possuem alicerces variados, desde a plausível concepção de discriminação reversa até defesa da propriedade privada. Para Tostes (2004), o emprego de quotas limita a discricionariedade que, v. g., um empresário tem de contratar, ou seja, “a 'ação afirmativa' viola o direito de propriedade e, consequentemente, o direito que um indivíduo tem de dispor de sua propriedade de acordo com seus próprios critérios”. A discussão não encerra apenas no contexto do direito à propriedade, a refutação à ação afirmativa ganha enfoques radicais como o entendimento de Tostes (2004) ao disciplinar que:

Subsidiar um indivíduo porque ele é negro resultará no aparecimento de mais 'negros' a clamar por subsídios; subsidiar os pobres levará a mais pobreza; subsidiar os desempregados trará mais desemprego; promover qualquer tipo de redistribuição coercitiva de renda, seja dos pobres para os ricos (inflação, protecionismo), seja dos ricos para os pobres (imposto sobre herança, sobre a propriedade, sobre 'grandes fortunas'), resultará no empobrecimento de todos; subsidiar políticos, agências 'reguladoras', cineastas, setores 'estratégicos' da economia, ONGs, pesquisa científica, universidades públicas, bolsa-escola etc. levará a um aumento do número de parasitas e do incentivo à parasitagem; e por que somente os negros? Onde estão os outros ‘excluídos' pelo 'capitalismo selvagem que aí está'? E os índios, as mulheres, os gordos, os tímidos, os 'sem-teto', os 'sem-terra', os homossexuais etc.? Toda essa engenharia social, é claro, só pode nos levar a uma direção: o colapso.

O entendimento acima transcende a discussão racional acerca da questão da ação afirmativa e da discriminação racial, deixando a aparência de uma posição equivocada do próprio conceito de lógica. Tais posicionamentos já foram profetizados por Silva (2004) ao afirmar que:

Certamente haverão alguns 'puristas', especialmente 'o branco receoso de perder nacos dos privilégios multisseculares de que desfrutam ou os membros do establishment jurídico', que irão levantar inúmeras questões em desfavor da implementação de um sistema de cotas em nosso país, especialmente, porque o aparato legal brasileiro não é muito explícito nesse sentido.

Neste diapasão, há de se revelar que a própria concepção norte-americana atual acerca do estabelecimento de quotas direciona entendimento diverso do que a política brasileira está propensa a seguir. Menezes (2001, p.31) ensina que:

O sistema de 'quotas', de fato, praticamente não é utilizado nos Estados Unidos, na atualidade, por ser considerado inconstitucional. No caso, entendese que esse método impõe um tratamento discriminatório contra certas pessoas (aquelas que não integram o grupo beneficiado com o programa de ação afirmativa), o que normalmente é feito com base em critérios vedados pela Constituição ou pela legislação ordinária ('v. g.' raça). Outrossim, uma 
série de pesquisas realizadas nas últimas duas décadas também revela que a opinião pública não aprova este sistema, embora seja favorável a outras formas de ação afirmativa, como a oferta de treinamento profissional complementar para grupos marginalizados.

Quer nos parecer que o cuidado atual, ou mesmo receio, de ocorrência de discriminação reversa tem sua razão de ser. Ao mesmo passo que um erro não pode justificar outro, muito mais quando os sujeitos a serem penalizados divergem dos verdadeiros algozes, não se pode olvidar da necessidade do emprego de programas de ação afirmativa em favor dos cidadãos negros, assim como de mulheres e deficientes físicos, diante da marginalização que eles próprios e toda a sociedade os condicionam. O Brasil está entendendo que a instituição de quotas é a solução, todavia, entendemos que empregar as quotas como sendo o único programa de ação afirmativa para as necessidades brasileiras consiste numa decisão errônea.

Brancos pobres também se encontram na marginalidade societária, também encontram dificuldades ao acesso no mercado de trabalho e ensino superior de qualidade. Esta consideração há de ser ponderada, a par das críticas de que se trata de mera escusa ao emprego das quotas. Não se trata de mera polemização, mas num fato real, a ação afirmativa, com o emprego de quotas, trará uma discriminação reversa! Ademais, entendemos que destinar quotas, por si só, aos discriminados racialmente, representa uma falácia política, posto que há de se ter uma construção prévia, anterior à inserção de um cidadão negro num emprego público ou Universidade Federal.

Tal medida significa muito mais positivar o racismo e levantar a revolta em torno da discriminação reversa que propriamente colaborar na mudança cultural, da atitude ao comportamento de que homem é homem independente de sua cor, credo, origem, etc. É preferível, antes mesmo de tais medidas, como diz o dito, ensinar a pescar, e não simplesmente entregar o peixe, ou seja, há que se fomentar o acesso e a permanência do negro do ensino fundamental até o médio, dar a ele condições educacionais de competividade, posto que sua capacidade de inteligência não é inferior a do branco quando em condições igualitárias de estudo. Assim, o próprio respeito ao cidadão negro se estabelecerá como conseqüência natural, ganhando ele, por suas próprias qualidades e esforços, assim como o branco, os postos que almejar. Lembremos que o que representa utopia hoje, pode consistir num fato amanhã, vide a própria ação afirmativa.

Entretanto, o até então exposto buscou apenas retratar os posicionamentos que circundam a contenda da ação afirmativa. Para uma discussão mais apurada do sistema de quotas há que se analisar em conjunto o próprio ordenamento jurídico pátrio, conforme segue.

\section{Ação Afirmativa, quotas e o ordenamento jurídico pátrio.}

Como já afirmado, o legislador brasileiro entendendo pela necessidade do emprego da ação afirmativa adotou o uso de quotas como medida solucionadora, quando não reparadora das necessidades atuais, levando-se em conta a discriminação racial existente no país. Dessa forma, várias legislações foram criadas. Silva (2004) destaca dentre os principais os seguintes textos legais:

I. Decreto-Lei 5.452/43 (CLT), que prevê, em seu art. 354, cota de dois terços de brasileiros para empregados de empresas individuais ou coletivas. II. Decreto-Lei 5.452/43 (CLT), que estabelece, em seu art. 373-A, a adoção de políticas destinadas a corrigir as distorções responsáveis pela desigualdade de direitos entre homens e mulheres. III. Lei 8.112/90, que prescreve, em art. 50, § $2^{\circ}$, cotas de até $20 \%$ para os portadores de deficiências no serviço público civil da união. IV. Lei 8.213/91, que fixou, em seu art. 93, cotas para os portadores de deficiência no setor privado. V. Lei 8.666/93, que preceitua, em art. 24, inc. XX, a inexigibilidade de licitação para contratação de associações filantrópicas de portadores de deficiência. VI. Lei 9.504/97, que preconiza, em seu art. $10, \S 2^{\circ}$, cotas para mulheres nas candidaturas partidárias. 
Cumpre lembrar, uma vez mais, que as ações afirmativas não se direcionam exclusivamente para os problemas da discriminação racial, daí a menção acima, por Luiz Fernando Martins da Silva, de legislações que englobam a defesa dos direitos das mulheres e dos deficientes físicos. No entanto, há que se sobressaltar que as verdadeiras polêmicas se encerram quando da instituição de quotas para os negros. Silva (2004) mesmo acrescenta que:

Recentemente as polêmicas sobre a implementação de ações afirmativas e cotas em nosso país aumentaram, notadamente, quando foram editadas leis estaduais reservando cotas para alunos negros e pardos nas Universidades públicas. Por exemplo, no Estado do Rio de Janeiro, a Lei $n^{\circ}$ 3708, de 9 de novembro de 2001, disciplinada pelo Decreto $\mathrm{n}^{\circ}$ 30.766, de 04 de março de 2002, instituiu cota de até $40 \%$ (quarenta por cento) para a população negra e parda no acesso à Universidade do Estado do Rio de Janeiro e à Universidade Estadual do Norte Fluminense.

O crescente debate em torno dos programas de ação afirmativa voltados para a discriminação racial, a inferiorização das mulheres e a marginalização dos deficientes físicos tem sido alvo de razoáveis debates, todavia, de precipitadas atitudes legiferantes. Aliás, o legislador pátrio tem por hábito lançar a lei, para após discuti-la com a sociedade organizada, o que motiva contendas mil, enxovalhando o Poder Judiciário seja em razão da má interpretação ou lacunas existentes nestes textos legais, seja por restarem eivados de inconstitucionalidade.

A questão começa a se sedimentar no cotidiano. A socióloga Rosana Heringer (2002, p.56), em excelente estudo levantou, tão-somente de setembro de 2001 a junho de 2002, ocasião em que as discussões pós-Durban se afloravam, várias propostas de ação afirmativa no Brasil. Assim é que, em síntese, se pode verificar um levantamento da socióloga onde se constatam que:

a) o Ministério do Desenvolvimento Agrário, o Supremo Tribunal Federal e o Ministério da Justiça possuem projeto de adoção de cotas para negros, mulheres e portadores de necessidades especiais nas empresas prestadoras de serviço às referidas Instituições, sendo os seguintes benefícios: $20 \%$ das vagas para negros, $20 \%$ para mulheres e $5 \%$ das vagas para portadores de necessidades especiais.

b) O Decreto Presidencial n. ${ }^{\circ} 4.228 / 02$, institui o Programa Nacional de Ações Afirmativas. Este programa prevê a realização de metas percentuais de participação de afrodescendentes, mulheres e pessoas portadoras de deficiência no preenchimento de cargos de comissão (DAS).

c) O Plano Nacional de Direitos Humanos tem também a ambição de adotar no âmbito da União e estimular a adoção, pelos Estados e Municípios, medidas de caráter compensatório que visem à eliminação da discriminação racial e à promoção da igualdade de oportunidades, tais como: ampliação do acesso dos afrodescendentes às Universidades públicas, aos cargos e empregos públicos.

d) O Instituto Rio Branco, possui projeto de criação de bolsas de estudo para afrodescendentes em cursos preparatórios para o Instituto Rio Branco, responsável pela formação de diplomatas brasileiros; serão 20 bolsas anuais pagas em 10 parcelas de R\$ 1 mil. Valores que sofreram aumento neste ano de 2004.

e) O Ministério da Educação apoia projetos de diversidade da Universidade, tais como cursos prévestibulares para afro-brasileiros e carentes, com o apoio do BID. Além de a atual gestão apoiar o emprego de quotas para negros nas Universidades.

f) A Universidade do Rio de Janeiro, por meio da Lei n. ${ }^{\circ}$ 3.708/01, sancionada em 05/05/2002, determinou a reserva de $40 \%$ das vagas das Universidades estaduais para "negros e pardos".

g) A Universidade Estadual da Bahia destina 40\% das vagas de todos os cursos da graduação e pósgraduação (mestrado e doutorado) para afrodescendentes, considerados os pretos e pardos segundo o IBGE. 
Como se pôde verificar, o estabelecimento de políticas de quotas tem sido o alvo do poder público quando do emprego de ações afirmativas, assim como se pode aferir que tais condutas resumem-se em ações tomadas univocamente por entes públicos, com apenas sugestões para a iniciativa privada. Inelutável, contudo, o entendimento de que já se trata de um grande avanço a instituição do Programa Nacional de Ações Afirmativas, sob a coordenação da Secretaria de Estado dos Direitos Humanos do Ministério da Justiça, no âmbito da Administração Pública Federal, através do Decreto n. ${ }^{\circ}$ 4.228, de 13 de maio de 2002. No entanto, também de todo salutar a advertência de Santana (2004) ao afirmar que:

Há que se ter certo cuidado com as expectativas depositadas em relação às possibilidades das políticas de ação afirmativa. O impacto dessas políticas a eficácia delas, está diretamente ligada ao grau de mobilização do público beneficiário. Não podemos esquecer que tanto na experiência dos negros norte americanos quanto dos sulafricanos, ações afirmativas, que não se reduz a cotas, foram conquistadas a custa de um alto grau de tensão social, de protestos de milhões com feição de guerra civil, o que não é o caso do Brasil, país cujo solo social produziu um tipo de racismo de conteúdo brutalmente perverso, de face mascaradamente brincalhona e imobilizador da ampla maioria de suas vítimas.

Por mais estas razões é que se deve promover maiores discussões em torno de outras medidas de ação afirmativa que não apenas as quotas, geradoras de polêmicas e inevitável discriminação reversa. Nesta senda também segue o entendimento do Ministro do Supremo Tribunal Federal, Joaquim B. Barbosa Gomes, que leciona faltar no Direito pátrio um mais profícuo conhecimento das possibilidades viabilizadas quando do emprego da affirmative action. Diz, ainda, que "entre nós, fala-se quase exclusivamente do sistema de cotas, mas esse é um sistema que, a não ser que venha amarrado a um outro critério inquestionavelmente objetivo, deve ser objeto de uma utilização marcadamente marginal” (SILVA, 2004).

Dessarte, políticas outras de ação afirmativa devem ser testadas no combate ao preconceito de modo geral, em especial à discriminação racial. Para tanto, há que se aprofundar, também, a discussão acerca da constitucionalidade dos programas de ação afirmativa, a fim de viabilizar o emprego de novas técnicas de ação afirmativa.

Neste diapasão, pode-se depreender de nossa Lei Fundamental que esta não tratara com especificidade da ação afirmativa, como legislações infraconstitucionais começam a apontar. Todavia, constam em seu texto princípios que dão permissibilidade a ações como esta, vide que a República apresenta como objetivos fundamentais, a construção de uma sociedade livre, justa e solidária, além da erradicação da pobreza e da marginalização e redução das desigualdades sociais (artigo $3^{\circ}$ ). O artigo $5^{\circ}$ ainda estampa em seu 'caput' e inciso I o princípio da igualdade.

Já no preâmbulo, verifica-se que o Constituinte, ao instituir o Estado Democrático destinou a este a obrigação de assegurar "a igualdade e a justiça como valores supremos de uma sociedade fraterna, pluralista e sem preconceitos, fundamentada na harmonia social”, de onde se pode extrair inúmeras autorizações legais e judiciais. Não bastassem tais disposições, a República Federativa do Brasil, por meio de sua Constituição, declara adotar o princípio de repúdio ao racismo (artigo $4^{\circ}$, VIII), inclusive considerando crime inafiançável a sua prática (artigo $5^{\circ}$, XLII). Também o acesso à educação será norteado segundo o princípio da igualdade de condições (artigo 206, I). Isto tudo somente limitandose ao contexto da discriminação racial.

Vislumbrada tais disposições, consideramos que está assegurada constitucionalmente a possibilidade de criação de medidas de ação afirmativa. No entanto, isso não quer significar que toda modalidade de ação afirmativa está garantida. Sem a pretensão de polemizar, concebemos serem inconstitucionais medidas que afrontam drasticamente o princípio da igualdade, como por exemplo, a instituição de quotas com os percentuais esdrúxulos hodiernamente apresentados, visto tratar, inegavelmente, de uma 
discriminação reversa, não aceita pelo sistema constitucional. Não fosse assim estaria a se afirmar que a igualdade presente na Constituição Federal de 1988 é diferente conforme a cor do cidadão, o que é ululantemente um absurdo. Se há igualdade para todos, todos são todos e não alguns. Assim, o cidadão negro tem todos os direitos constitucionais, tanto quanto o pardo, o branco e todas as demais classificações desnecessárias.

Contudo, que se deixe patente, outras técnicas de ação afirmativa podem não ferir drasticamente as disposições constitucionais e assim serem eivadas de total licitude. Dizemos drasticamente por entendermos que de uma forma ou de outra o próprio princípio da igualdade será afetado com a ação afirmativa, visto seus objetivos e seu próprio conceito. No entanto, a tolerância a determinadas ações afirmativas pode enquadrar-se em limites onde não se vê perigo à própria segurança jurídica, como ocorre nos diversos concursos em que se reservam $5 \%$ das vagas para deficientes. Ora, 5\% é um percentual proporcionalmente razoável e aceitável pela coletividade, visto a discriminação que sofre o deficiente na iniciativa privada.

No entanto, o estabelecimento de $40 \%$ para cidadãos “pretos e pardos”, conforme dispõe a UnbUniversidade Estadual da Bahia, consiste num percentual aberrador, pois logo se estará reservando mais $5 \%$ ou $10 \%$ para deficientes, mais $20 \%$ ou $30 \%$ para as mulheres, e o cidadão branco e pobre, numa hipótese possível, contaria com apenas de 20\% a 35\% das vagas, o que demonstraria uma frontal violação ao princípio constitucional da igualdade. Por certo, tal hipótese jamais chegaria à vigência, no entanto, a possibilidade, segundo o próprio levantamento da socióloga Rosana Heringer acima, já dão mostras de alguns indícios deste abuso. De qualquer forma, correto é o entendimento de Menezes (2001, p.152) ao considerar que:

A ação afirmativa não se choca, 'a priori', com os ditames constitucionais pátrios. No entanto, em virtude das cristalinas diferenças existentes entre o ordenamento jurídico brasileiro e o norte-americano (nos quais se destacam as doutrinas adotadas na aplicação da 'equal protection clause' e a possibilidade de uma 'interpretação construtiva' do direito pelos magistrados norte-americanos), não julgamos ser possível preestabelecer padrões genéricos e absolutos para a instituição de políticas de ação afirmativa.

Com isso, queremos dizer que a constitucionalidade de questões envolvendo a matéria terá de ser, necessariamente, investigada em cada situação concreta, segundo o método de averiguação do princípio da igualdade jurídica, consagrado entre nós.

Esta afirmação demonstra-se de todo sensata, e deveria passar a ser perquirida em ato cognitivo pelo próprio legislador antes da elaboração de projetos de lei que circundam a temática da ação afirmativa, mormente quando se cogita estabelecimento de quotas.

\section{À guisa de conclusão: ação afirmativa e cidadania}

Ao concluirmos o singelo estudo cumpre ainda trazer resposta à indagação de que se a ação afirmativa consiste num instrumento promotor da cidadania. Em preliminar temos que, historicamente, a cidadania tem sido entendida como o exercício dos direitos civis, dentre eles o voto. Moás (2002, p.7) ministra que "para a civilização greco-romana, cidadãos eram apenas aqueles que participavam ativamente do funcionamento da cidade-Estado através da votação das leis e do exercício de funções públicas.” Já para Herkenhoff (2001, p.33):

A história da cidadania é, de certa forma, a própria história dos direitos humanos e a história das lutas para a afirmação de valores éticos como a igualdade, a liberdade, a dignidade de todos os seres sem exceção, a proteção legal dos direitos, a sacralidade do trabalhador, a democracia e a justiça. 
Consideradas tais noções históricas, parcialmente vigentes hodiernamente, assim como as lutas, também pretéritas, das organizações e movimentos negros norte-americanos e que se verificam também no Brasil, embora com as nossas próprias características, temos que a ação afirmativa realmente representa um instrumento promotor da cidadania. Isso se deve ao fato de que, a cidadania é, na verdade, a luta pela eficácia dos direitos garantidos pelas leis e Constituições, a fomentação de propostas para positivação de direitos ainda não concebidos. E em se tratando da ação afirmativa numa luta dos marginalizados, mormente daqueles em decorrência da discriminação racial, indiscutivelmente está servindo a ação afirmativa como um instrumento para a construção da cidadania.

Entendemos que a união de um determinado grupo de indivíduos na defesa ou construção de delineadas propostas e/ou direitos, por si só, já dão conta de se estar efetivando o exercício da cidadania. Moás (2002, p.20), neste escólio, ensina "que falta no ordenamento pátrio a percepção de que os direitos e deveres listados na atual Constituição, para a sua efetiva realização, dependem do exercício da cidadania através da participação política dos cidadãos”.

Essa questão circunda a democracia, pois o escopo de se alcançar a igualdade jurídica traduz, em conseqüência, a sedimentação da democracia. Assim, Moás (2002, p.19) verifica que há “a necessidade de, a partir de agora, a cidadania ser analisada sob a perspectiva do processo democrático".

Dessarte, conclui-se que, embora nosso entendimento de que as quotas representam uma discriminação reversa, inolvidável que as discussões, ora mais ora menos acirradas acerca da instituição de quotas para cidadãos negros e pardos, no fundo, consistem no exercício de cidadania no tocante a junção de forças críticas para que direitos sejam garantidos e efetivamente viabilizados, como de fato já se apontam, enquanto preconceitos e discriminações arcaicas sejam banidas da realidade fática.

\section{Referências}

HERINGER, Rosana. Ação afirmativa, estratégias pósDurban. Rio de Janeiro: Observatório da Cidadania-Brasil: Ibase, 2002. p.56. Disponível em: <http:// www.socwatch.org.uy/es/informeImpreso/pdfs/ panorbrasileirob2002_bra.pdf $>$. Acesso em: 29 mar. 2004.

HERKENHOFF, João Baptista. Como funciona $a$ cidadania. 2. ed. Manaus: Valer, 2001. p.33.

INOCÊNCIO, Nelson Olokofá. Ações Afirmativas: um olhar do movimento negro. Assessoria de Comunicação: UnB, 2004. Disponível em: <http://www.unb.br/acs/ acsweb/artigos/olokafa.htm>. Acesso em: 31 mar. 2004.

MENEZES, Paulo Lucena de. A ação afirmativa (Affirmative action) no direito norte-americano. São Paulo: Revista dos Tribunais, 2001. 174p.

MOÁS, Luciane da Costa. Cidadania e Poder Local. Rio de Janeiro: Lúmen Júris, 2002. 116p.

OLIVEIRA, Eduardo H. P. de. Além do nada: Estado, raça e ação afirmativa. Estudos e Projetos: Cidadania: Brasília. Disponível em: <http://www.intelecto.net/cidadania/ nada.htm>. Acesso em: 1 abr. 2004.

POLETTI, Ronaldo Rebello de Britto. Ações Afirmativas. Brasília: UnB. Disponível em: <http://www.unb.br/fd/ colunas_Prof/ronaldo_poletti/ poletti_15.htm $>$. Acesso em: 29 mar. 2004.

SANTANA, Olívia. Ações Afirmativas: limites e possibilidades. Bahia: UFBA. Disponível em: <http:// www.faced.ufba.br/destaques/olivia_santana/ olivia_santana_acoes_afirmativas.htm>. Acesso em: 29 mar. 2004.

SEVERINO, Antônio Joaquim. Uma proposta de ação afirmativa anti-racista no campo da educação. Revista Espaço Acadêmico, Maringá, Ano II, n.23, abr. 2003. Disponível em: <http://www.espacoacademico.com.br/023/ 23cseverino.htm>. Acesso em: 29 mar. 2004.

SILVA, Luiz Fernando Martins da. Sobre a implementação de cotas e outras ações afirmativas para os afrobrasileiros. Disponível em: <http://www.achegas.net/ numero/cinco/_ffernando_2.htm>. Acesso em: 1 abr. 2004.

TOSTES, Marcello. A ação afirmativa e os argumentos "racionais". O Indivíduo. Disponível em: <http:// www.oindividuo.com/convidado/tostes8.htm>. Acesso em: 29 mar. 2004. 
